\title{
Stage II Pancreatic Cancer AJCC v6 and v7
}

National Cancer Institute

\section{Source}

National Cancer Institute. Stage II Pancreatic Cancer A/CC v6 and v7. NCI Thesaurus. Code $C 7786$.

Stage II includes: IIA (T3, N0, M0); IIB (T1, N1, M0); (T2, N1, M0); (T3, N1, M0). T1:

Tumor limited to the pancreas $2 \mathrm{~cm}$ or less in greatest dimension. T2: T umor limited to the pancreas, more than $2 \mathrm{~cm}$ in greatest dimension. T3: T umor extends beyond the pancreas but without involvement of the celiac axis or the superior mesenteric artery. N0: No regional lymph node metastasis. N1: Regional lymph node metastasis. M0: No distant metastasis. (AJCC 6th and 7th Eds.) 